\title{
Aplasia cutis congenita of the scalp- what are the steps to be followed? Case report and review of the literature*
}

\author{
Piotr Brzezinski ${ }^{1}$ \\ Anca E Chiriac ${ }^{2}$ \\ Anca Chiriac $^{3}$
}

\author{
Tudor Pinteala ${ }^{2}$ \\ Liliana Foia ${ }^{2}$
}

DOI: http://dx.doi.org/10.1590/abd1806-4841.20153078

\begin{abstract}
Aplasia cutis congenita is a rare malformation characterized by localized congenital absence of the skin. It rarely occurs on the trunk and limbs, and can occur in isolation or as part of a heterogeneous group of syndromes. We report a case of a 4-day-old boy with a 5.6-cm- diameter tumor, with a central crust, non-indurate and no inflammatory rim; localized on the scalp and a small, atrophic hairless scar appeared 6 months later (approximately $5 \mathrm{~cm}$ in length) at the site of the previous tumor.
\end{abstract}

Keywords: Ectodermal dysplasia; Scalp; Skin diseases

\section{INTRODUCTION}

Aplasia cutis congenita (ACC) is a rare malformation characterized by localized congenital absence of the skin. It rarely occurs on the trunk and limbs, and can occur in isolation or as part of a heterogeneous group of syndromes. ${ }^{1}$ It is a focal deficiency of cutaneous tissues of arying severity, ranging from an absence of skin through to full thickness defects involving deeper elements such as bone and dura. Lesions of the scalp can be associated with complications including infection, hemorrhage, thrombosis, and seizures. The lesion was first described in 1767 by Cordon, though the first scalp aplasia cutis was described later, in 1826, by Campbell. Since then, hundreds of cases have been reported all over the world. The incidence of aplasia cutis is $0.5 / 10,000$ to $1 / 10,000$ newborns; the ratio female/male newborns is around $7: 5 .^{2}$

\section{CASE REPORT}

A 4 day-old boy was sent to us for an opinion on an ulcerated-crusted tumor on the vertex, observed 24 hours prior to the call from the Neonatology Department (Figure 1).
Dermatological examination revealed a 5.6-cmdiameter tumor, with a central crust, non-indurate and no inflammatory rim; localized on the scalp, $1.5 \mathrm{~cm}$ left of the midline. The newborn was otherwise healthy, with APGAR 10 at birth, young parents with no consanguinity or known medical problems. No visible or palpable scalp defect was found at the first examination. Local wound care was done with simple povidine iodine. The clinical diagnosis was aplasia cutis congenital and the main task (a difficult one) was to reassure the parents and medical staff from the Neonatology Department, instructing them simply to wait and observe the evolution of the skin lesion. There were no signs of infections and/or hemorrhages; no skull defects or other abnormalities.

The parents did not agree to a skin biopsy or complete removal of the tumor despite the recommendation from pediatricians, while pediatricians from the Neonatology Department did not approve an MRI.

Received on 23.08.2013.

Approved by the Advisory Board and accepted for publication on 21.10.2013.

* Work performed Department of Dermatology, Nicolina Medical Center - Iasi, Romania.

Conflict of interest: None

Financial funding: None 


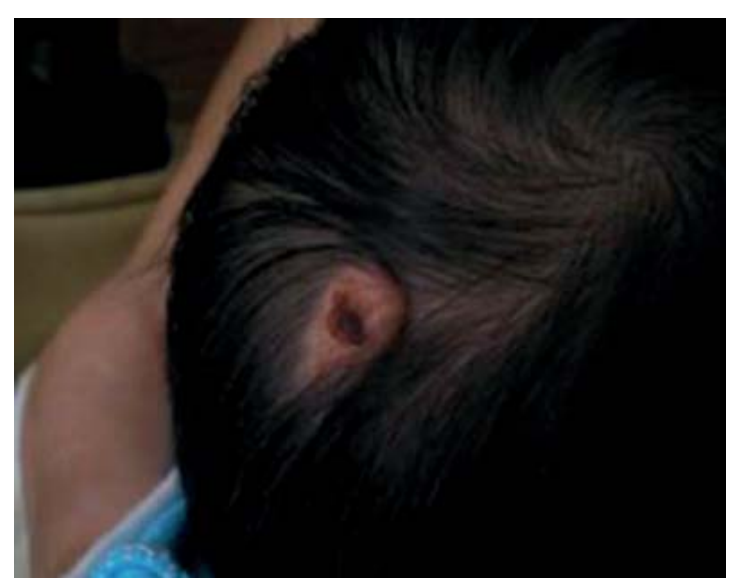

FigURE 1: Ulcerated tumor on the scalp

A reexamination was done 6 months later, revealing only a small, atrophic hairless scar of approximately $5 \mathrm{~cm}$ in length, at the site of the previous tumor (Figure 2).

\section{DISCUSSION}

Aplasia cutis congenita (ACC) is a rare malformation characterized by localized absence of the skin, mostly on the scalp, but also on any part of the body. ${ }^{1}$

In most cases, Aplasia cutis congenital is observed (by family members or medical staff) during the first days of life, as a single lesion on the vertex lateral to the median line, although reports of different locations (face, trunk, abdomen, limbs) have recently been published. ${ }^{1,3}$ The typical lesion is small $(0.5 \mathrm{~cm}$ $10 \mathrm{~cm})$, well circumscribed, with different aspects: circular, oval, linear or stellate, membranous (membranelike surface) or non-membranous (irregular and larger). ${ }^{4}$ Aplasia cutis may be associated with defects of the underlying skull, especially when the skin lesion is larger than $10 \mathrm{~cm}$. This is an important clinical clue when considering associated malformations or possi-

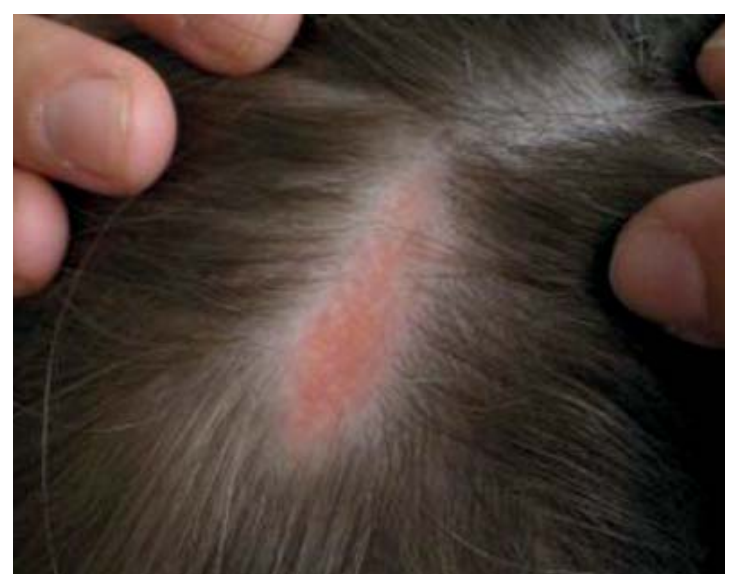

FIGURE 2: Atrophic scar ble complications (sagittal sinus hemorrhage or thrombosis, focal infection or meningitis), important causes of death. ${ }^{5}$ The lesion is non-inflammatory and circumscribed. The clinical aspect may inform about the moment of induction during pregnancy: early in the first weeks, there is time for healing and the lesion appears as an atrophic or fibrotic alopecic scar.

In some cases, deeper defects can be observed: ulcerations that go through the dermis, subcutis, periosteum, even the skull and dura, with severe complications.

The hair collar sign (distorted hair growth around a scalp lesion) is a significant indicator, raising the question of underlying injuries. The location of the ACC to the vertex can be explained partially by the existence of maximum tensile force during rapid brain growth in that region; this happens during weeks 1015 of gestation.

The exact mechanism is still not completely understood, although many etiological factors have been incriminated in recent years: ${ }^{4}$

- chromosomal abnormalities,

- traumatic mechanism,

- amniotic defects,

- intrauterine problems,

- thrombotic events, vascular alterations.

- teratogens used in pregnancy: misoprostol,

cocain, methotrexate, angiotensin-converting enzyme inhibitors, methimasol, benzodiazepines, valproic acid. ${ }^{7.8}$

Most cases are sporadic but genetic backgrounds (autosomal dominant and recessive inheritance) have also been reported; the large ulcerated lesions are often transmitted as an autosomal dominant trait. ${ }^{4,9}$ In the great majority of cases, the evolution is without complications and simple wound care is suitable. Complications that can aggravate the prognosis (such as hemorrhage, local infection, meningitis or more severe sagital sinus thrombosis), are rarely reported. There have been reports of seizure and psychomotor retardation. ${ }^{10}$

However, the most important issue concerns the associated anomalies that pose many practical problems to medical staff.

There is no consensus regarding treatment. Options include monitoring and surgical intervention; but the rule is that in cases of large lesions, with or without deeper absence of substance, plastic surgery should be performed as soon as possible. Frieden proposed a classification (Chart 1) that is of great value for daily practice, ${ }^{5}$ consisting of 9 groups based on the number and location of the lesions, and the presence or absence of associated malformations.

We recommend the following procedure for ACC workups: 
CHART 1: Classification of Aplasia cutis congenita by Frieden

\begin{tabular}{|c|c|c|}
\hline Type & characteristics & Transmission \\
\hline 1 & scalp ACC without multiple anomalies & AD or sporadic \\
\hline 2 & $\begin{array}{l}\text { Scalp ACC with limb anomalies: } \\
\text { - distal limb reduction (Adams-Oliver syndrome) } \\
\text { - hypoplastic or absent distal phalanges } \\
\text { - cutis marmorata telangiectatica congenita, hemangiomas, cranial arteriovenous } \\
\text { malformation, skin tags, supernumerary nipples, and woolly hair }\end{array}$ & $\mathrm{AD}$ \\
\hline 3 & $\begin{array}{l}\text { Scalp ACC with epidermal nevus syndrome ophtalmic and neurologic problems: (seizu- } \\
\text { res, mental retardation, corneal opacities, and eyelid colobomas) }\end{array}$ & sporadic \\
\hline 4 & $\begin{array}{l}\text { ACC with embryologic malformations: meningomyelocele, porencephaly, leptomeningeal } \\
\text { angiomatosis, cranial stenosis, spinal dysraphism, gastroschisis, and omphalocele }\end{array}$ & variable \\
\hline 5 & $\begin{array}{l}\text { ACC associated with fetus papyraceous (results from the death of a twin fetus in the } \\
\text { second trimester) or placental infarct; ACC is extensive on the trunk or limbs, linear or } \\
\text { stellate configuration. }\end{array}$ & sporadic \\
\hline 6 & ACC (on lower extremities) associated with epidermolysis bullosa & $\begin{array}{l}\text { depends on the type of } \\
\text { epidermolysis bullosa: } \\
\text { AD or AR }\end{array}$ \\
\hline 7 & ACC on the extremities without epidermolysis bullosa & $\mathrm{AD}$ or $\mathrm{AR}$ \\
\hline 8 & $\begin{array}{l}\text { ACC caused by teratogens: intrauterine infection with herpes simplex virus/varicella- } \\
\text { zoster virus, methimazole, carbimazole treatment during pregnancy }\end{array}$ & not inherited \\
\hline 9 & $\begin{array}{l}\text { ACC associated with malformation syndromes: } \\
\text { - trisomy } 13 \text { (Patau syndrome) } \\
\text { - } 4 \text { p-(Wolf-Hirschhorn) syndrome } \\
\text { - Setleis syndrome } \\
\text { - Johanson-Blizzard syndrome } \\
\text { - focal dermal hypoplasia (Goltz syndrome), } \\
\text { - amniotic band disruption complex, } \\
\text { - oculocerebrocutaneous (Delleman) syndrome, } \\
\text { - } \text { scalp-ear-nipple syndrome (Finlay-Mark syndrome), } \\
\text { - Kabuki syndrome, }\end{array}$ & variable \\
\hline
\end{tabular}

AD: autosomal dominant; AR: autosomal recessive

1. lab investigations are within normal range and there are no specific tests

2. radiographs of the scalp, extremities should be performed in special cases;

3. skin biopsy and histopathological report: the absence of (or very thin) epidermis, of the dermis or deeper structures; in the dermis, "loosely arranged" collagen bundles; the absence of adnexes and elastic fibers;

4. ultrasonography, MRI in case of associated malformations and complications;
5. prenatal tests suggesting ACC: $\boldsymbol{a}$-fetoprotein level in amniotic fluid and maternal blood, and positive acethylcholinesterase test in case of normal ultrasonography ; 9

6. history of drug-intake during pregnancy, endocrinological status of the pregnant woman, associated diseases;

7. genetic examination.punk-77 $\square$ 


\section{REFERENCES}

1. Verhelle NA, Heymans O, Deleuze JP, Fabre G, Vranckx JJ, Van den hof B. Abdominal aplasia cutis congenita: case report and review of the literature. $J$ Pediatr Surg. 2004;39:237-9.

2. Srinivasan SM. Expecting the most unexpected - a harlequin baby! A case report and literature analysis. Our Dermatol Online. 2012;3:321-5.

3. Ambika H, Sujatha Ch, Santhosh S. Amniotic bands with Infantile Digital Fibromatosis. Our Dermatol Online. 2012;4:232-3.

4. İsçimen A, Yardımcı G. Aplasia cutis congenita. J Turk Acad Dermatol. 2010;4:04201r

5. Burkhead A, Poindexter G, Morrell DS. A case of extensive Aplasia Cutis Congenita with underlying skull defect and central nervous system malformation: discussion of large skin defects, complications, treatment and outcome. J Perinatol. 2009;29:582-4

6. Buquicchio R. Gangrenous aplasia cutis congenita of the scalp. A marker of severe hemorrhage and epileptic attacks. Eur J Pediat Dermatol. 2009;19:91-4.

7. Karg E, Bereg E, Gaspar L, Katona M, Turi S. Aplasia cutis congenita after methimazole exposure in utero. Pediatr Dermatol. 2004;21:491-4.

8. Tasin L, Belli S, Chiodini E. Aplasia cutis congenita and methimazole. A case report and literature review. Eur J Pediat Dermatol. 2005:15:117-20.

9. Milano A. Aplasia cutis short report. Eur J Pediat Dermatol. 2013;23:50.

10. Bonifazi E. Bullous aplasia cutis. Eur J Pediat Dermatol. 2010;20:148.

\author{
MAILING ADDRESS: \\ Piotr Brzezinski \\ Department of Dermatology, \\ 6th Military Support Unit, \\ os. Ledowo $1 \mathrm{~N}$ \\ 76-270 Ustka, Poland. \\ E-mail:brzezoo@wp.pl
}

How to cite this article: Brzezinski P, Chiriac A, Pinteala T, Chiriac AE, Foia L. Aplasia cutis congenita of the scalp- what are the steps to be followed? Case report and review of the literature. An Bras Dermatol. 2015;90(1):100-3. 